\title{
Intelligent Web Information Service Model for Minimizing Information Gap Among People in E-Government
}

\author{
Gye Hang Hong ${ }^{1}$, Jang Hee Lee ${ }^{2}$, Tae Hyun $\mathrm{Kim}^{3}$, \\ Sang Chan Park ${ }^{3}$, Hyung Min $\mathrm{Rho}^{4}$, and Dong Sik Jang ${ }^{1}$ \\ ${ }^{1}$ Industrial System and Information Engineering, Korea University, Seoul, Republic of Korea \\ \{kistduck,jang\}@korea.ac.kr \\ ${ }^{2}$ Industrial Management, Korea University of Technology and Education, \\ Chunan, Republic of Korea \\ janghlee@kut.ac.kr \\ ${ }^{3}$ Industrial Engineering, Korea Advanced Institute of Science and Technology, \\ Daejeon Republic of Korea \\ \{imiss, sangchanpark\}@kaist.ac.kr \\ ${ }^{4}$ CADCAM center, Korea Institute of Science and Technology, Seoul, Republic of Korea \\ hmrho@kist.re.kr
}

\begin{abstract}
We suggested a web information service model for minimizing information gap among people. A difference of information access environment, ability to understand and information pursuit desire, etc among people makes people to use different kinds of information on their decision-making. We designed an intelligent web information service model, consisting of a web usage analysis and a personalized web service module.
\end{abstract}

\section{Introduction}

E-government is defined as an application of IT to government service [1]. An access to information service, one of the common e-government services provides various kinds of public information to the users having various demands for supporting their decision-making. Because education level, information pursuit desire, different network connection environment, and so on are different according to the users, the web service of government which does not consider these differences may not satisfy some users of them. For reducing these differences, many researches are developed in the fields of both web design and personalization.

Marchionini G. and M. Levi [2] suggested a design method where many kinds of information are contained in minimum pages and the same information is presented as the various different types, which all users can understand easily.

A personalization is that information about the specific user is used to develop an electronic profile based on different types of user-specific information. So, users can have benefit for reducing searching time of information [3].

We have formulated the following conjectures by examining the research results and the e-government environment.

Firstly, we verify that the information gap among advantaged people and disadvantaged people has an effect on difference of profit/loss in their economic behaviors. 
Secondly, we show that causes of the information gap occur from the level of understanding information among people. So, we identify the web pages, which advantaged people refer for their decision-making and the web pages, which disadvantaged people do. We analyze differences of the two kinds of web pages from the viewpoint of the dimension complexity and the decision variables.

\section{Current Web Information Service System of MAF in Korea}

A current public institution's web service system in MAF was made to deliver beneficial agriculture information to farmers. Web contents in the web service system of MAF are mainly statistic analysis of product transaction in market. Although the current system serves many kinds of web pages to satisfy various demands of users, the many kinds of web pages caused increase of searching time and some kinds of web pages could not be understood by some people because of summarizing data by many dimensions.

\section{Intelligent Web Information Service (IWIS) Model}

\subsection{Web Usage Analysis Module(WUAM)}

WUAM is defined as the module for identifying information gap between advantaged people and disadvantaged people, then discovering knowledge, key web pages and those dimensions and decision variables, for reducing the information gap.The WUAM discovers the knowledge by the following steps.

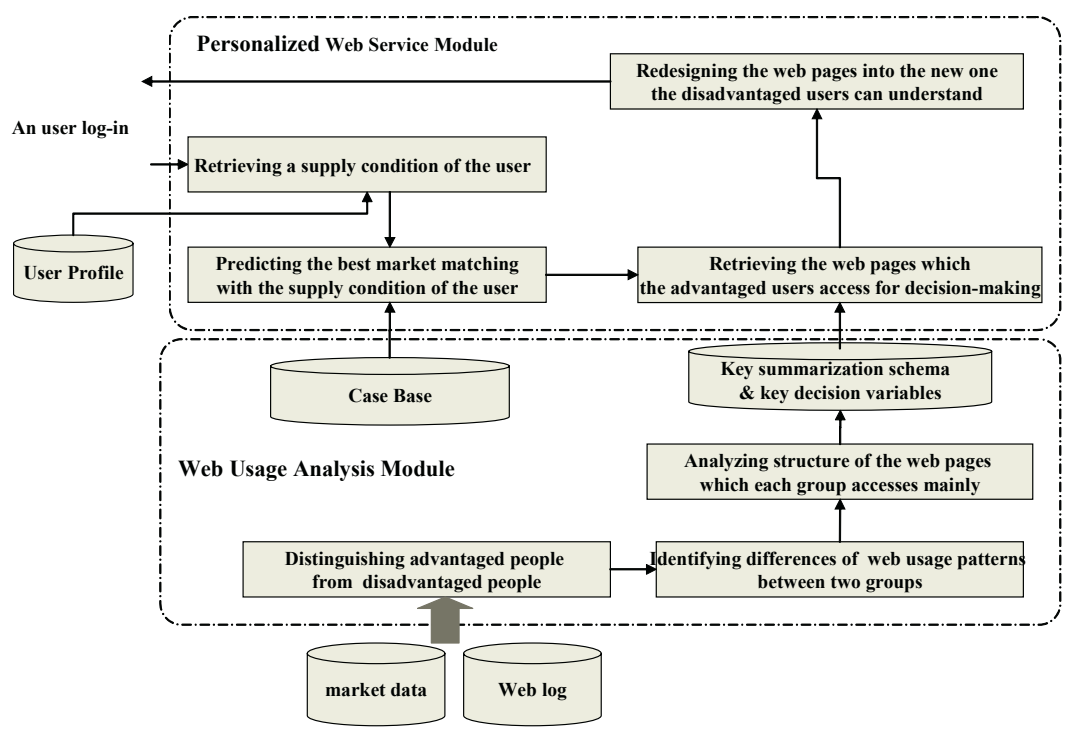

Fig. 1. Framework of our IWIS model

Firstly, we distinguish advantaged people from disadvantaged people in terms of three factors: Total Profit or loss (TP), Probability For Profit (PFP), and Probability 
For Loss $(P F L)$. By evaluating the factors simultaneously, we can distinguish advantaged people from the others. For evaluating the factors simultaneously, we segment people into several groups having a similar features with SOM(Self-OrganizingMap), one of the clustering methods [4].

Secondly, we identify differences of web usage patterns between advantaged group and disadvantaged group. The differences are the kinds of web page accessed for decision-making and the level of understanding information. The following sub-steps identify the difference of web pages accessed between two groups.

1) We calculate access count of user to web page by analyzing web-log data. The access count is transformed into one of the five levels: $\operatorname{High}(H), \operatorname{Low}(L)$, Average $(A)$, Above Average $(A A)$, and Below Average $(B A)$.

2) We identify the important web pages which can distinguish two groups. We use the C4.5 which is one of classification methods [5]. Table 1 shows the result of classification. Disadvantaged people think price and quality data a day as important information, while advantaged people think quantity and it's trend data a week as important information.

Table 1. Summary of the schema and decision variables characterizing each group

\begin{tabular}{|l|l|l|l|}
\hline & $\begin{array}{l}\text { No. web } \\
\text { pages }\end{array}$ & $\begin{array}{l}\text { Degree of } \\
\text { reference }\end{array}$ & Dimension and decision variable \\
\hline $\begin{array}{l}\text { Advantaged } \\
\text { people }\end{array}$ & A01 & <=AA & $\begin{array}{l}\text { Dimension: time(daily), item, market } \\
\text { Decision variables: price and quality }\end{array}$ \\
\cline { 2 - 4 } & A15 & $>$ A & $\begin{array}{l}\text { Dimension: time(week), market, supplier, item } \\
\text { Decision variables: quantities and its trend }\end{array}$ \\
\hline $\begin{array}{l}\text { disadvantaged } \\
\text { people }\end{array}$ & A01 & $>$ AA & $\begin{array}{l}\text { Dimension: daily, item, market } \\
\text { Decision variables: price and quality }\end{array}$ \\
\hline
\end{tabular}

\subsection{Personalized Web Service Module(PWSM)}

$P W S M$ is defined as the module for predicting the best decision-making under current supply condition of the user accessed in the system, then redesigning the web pages regarded to the best decision-making.

Firstly, we retrieve a supply condition of the accessed user from the user' profile database and market database.

Secondly, we predict the best market matching the supply condition of the user. We use a hybrid approach of Memory And Neural Network based learning (MANN) [6] for the prediction.

Thirdly, we retrieve the web pages which advantaged people mainly access for decision-making.

Lastly, we redesign the retrieved web pages into new one the disadvantaged people can understand easily.

Fig. 2 shows one of the redesigned web pages which the disadvantaged people can understand easily. Fig 2 (a) is web information, advantaged people access mainly, summarized according to four dimensions of item, supplier, market, and time. Because the web information consists of many web pages of combination of four dimensions, disadvantaged people consider many web pages for decision-making.

Therefore, we predict the good alternatives under condition of disadvantaged people, present the good alternatives by two dimension of time and item. Fig 2(b) shows 

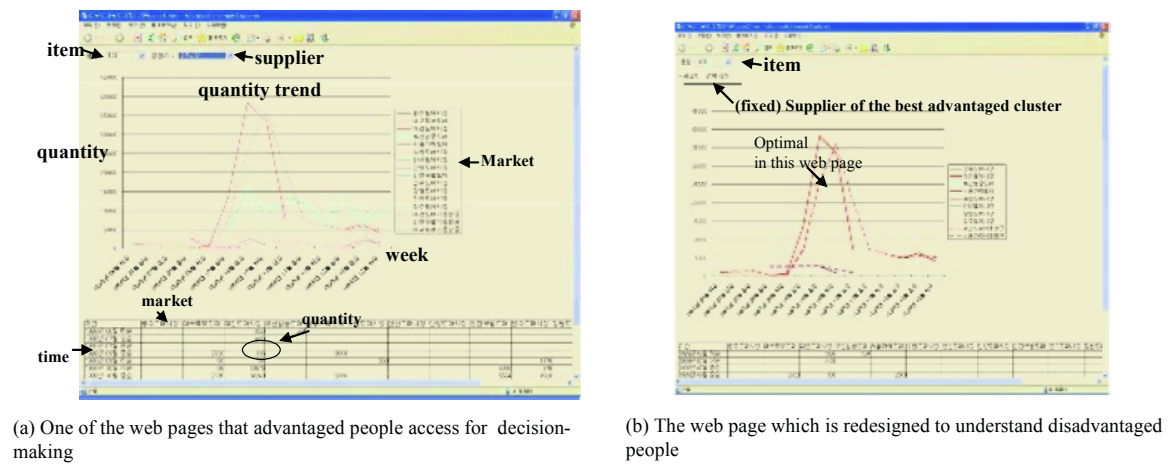

Fig. 2. Redesigning an web-page (Some Korean words were translated into English)

the redesigned web page summarized according to only item and time by fixing the optimal supplier and the optimal market. As a result, disadvantaged people consider a little of web pages and they can make the better decision.

\section{Conclusion}

Due to the differences of information access environment, the ability to understand information and the information pursuit desire, people use different kinds of information. To provide the losers with the same profit as a minimization of the information gap, we collected web-log data of users and profit data of the users. We divided people into the advantaged people and the disadvantaged people. We identified differences of web usage, web pages accessed mainly for decision-making and a level of understanding the web pages, between the two groups. Then, we identified important factors for decision-making by analyzing the dimension and decision variables included in the web pages used by the advantaged users. The factors and the level of understanding information of each group are used for a personalization service. If a user logged in the system, the system retrieved profiles of the user and the factors and predicted potential alternatives. Then the system designed information of the potential alternatives to a type of web pages which the user can understand easily.

\section{References}

1. Marchionini G., Sanan H., and L. Brabdt: Digital Government, Communications of the ACM, vol. 46, No.1 (2003) 25-27

2. Marchionini G., M. Levi: Digital Government Information Services: The Bureau of Labor Statistics Case, Interactions, Vol. 10 (2003) 18-27

3. Hinnant C. C. and J.A.O'Looney: Examining pre-adoption interest in on-line innovations: An exploratory study of e-service personalization in public sector, IEEE Transactions on engineering management, vol.50,No.4 (2003) 436-447.

4. T.Kohonen: Self-oranized formation of topologically correct feature maps, Biolog. Cybern., vol.43 (1982) 59-69.

5. Quinlan,J.R.: C4.5: Programs for machine learning, San Mateo, CA: MaGrw-Hill (1993).

6. C.K. Shin, U.T Yun, H.K. Kim and S.C. Park: A Hybrid Approach of Neural Network and Memory-Based Learning to Data Mining. Int J IEEE Trans. on Neural Networks. Vol.11, No.3 (2000). 